\title{
Controle das práticas periféricas: entre normas legais e pluralidades $^{123}$
}

\section{Control de prácticas periféricas: entre normas legales y pluralidades}

\section{Control of peripheral practices: between legal norms and pluralities}

\author{
Danielle Ferreira Medeiro da Silva de Araújo ${ }^{4}$ \\ Walkyria Chagas da Silva Santos ${ }^{5}$
}

\begin{abstract}
Resumo
O objetivo geral do artigo é refletir a estrutura social desigual brasileira, que ao mesmo tempo em que abarca uma pluralidade de modos de vida, na esfera das normas legais se impõe a partir de uma visão legítima de mundo sobre estilos de vida distintos, a imposição de normais legais nesses espaços, dentro de uma perspectiva racionalista e tecnicista, sustentada pelos princípios de generalidade e impessoalidade, muitas vezes desrespeitam o saber local da comunidade e são aplicados mediante verdadeira violência simbólica e pilhagem, mesmo que o discurso seja de garantia de direitos. Pretende-se relatar a partir de casos concretos, atuação das autoras em projetos de mediação comunitária de conflitos no estado do Rio de Janeiro e no estado Bahia. A metodologia do trabalho baseia-se na teoria fundamentada e o método utilizado foi a pesquisa bibliográfica realizada a partir dos registros disponíveis em fontes impressas e digitais sobre o Projeto Balcão de Direitos do ISER, do Programa Justiça Comunitária, ambos do estado do Rio de Janeiro, e do Balcão de Justiça e Cidadania, do estado da Bahia. Nas discussões as autoras analisam que os projetos de mediação comunitária de conflitos, são exemplos de tentativa de criação de uma ponte entre Estado e periferia para fomentar/construir um espaço participativo, e que inicialmente visam democratizar o acesso à justiça às populações de regiões periféricas, mas a prática pode resultar em violação de direitos.
\end{abstract}

Palavras-Chave: Projetos de mediação comunitária; normas sociais; normas legais; controle de práticas periféricas.

\footnotetext{
1 Artigo apresentado no II Congresso Internacional Online de Estudos sobre Culturas, na modalidade online, 2020.

${ }^{2} \mathrm{O}$ texto é resultado do diálogo de debates e de bibliografias realizado pelas duas autoras em igualdade.

${ }^{3}$ Versão reduzida do texto foi apresentada no CAED-JUS 2020 e será publicada como resumo em anais.

${ }^{4}$ Doutoranda do Programa de Pós-Graduação em Estado e Sociedade, da Universidade Federal do Sul da Bahia (UFSB). Integrante do grupo de pesquisa Paidéia - laboratório de pesquisas transdisciplinar sobre metodologias integrativas para a educação e gestão social. Integrante do Coletivo Dandaras. Docente de Direito na Faculdade Pitágoras e na Faculdade Nossa Senhora de Lourdes. Membra da Comissão de Diversidade e Enfrentamento à Intolerância da OAB - Subseção Eunapólis. Membra da Comissão Especial de Promoção da Igualdade Racial da Bahia. E-mail: dannymedeiro@hotmail.com

${ }^{5}$ Professora do Curso de Direito da Universidade Federal do Tocantins (UFT). Doutoranda do Programa de PósGraduação em Direito da Universidade de Brasília (UnB). Doutoranda do Programa de Pós-Graduação em Estado e Sociedade da Universidade Federal do Sul da Bahia (UFSB). Mestra em Gestão de Políticas Públicas e Segurança Social pela Universidade Federal do Recôncavo da Bahia (UFRB) (2015). Especialista em Gestão de Políticas Públicas em Gênero e Raça (2014) e em Direito do Estado (2009) pela Universidade Federal da Bahia (UFBA). Integrante do Grupo de Pesquisa MARÉ - Cultura Jurídica e Atlântico Negro (UnB). Integrante do Coletivo Dandaras (UFSB). Pesquisadora associada do Centro Latino-americano de Estudos em Cultura (CLAEC). E-mail: kyriachagas@yahoo.com.br
} 


\begin{abstract}
Resumen
El objetivo general del artículo es reflejar la desigual estructura social brasileña, que, si bien abarca una pluralidad de formas de vida, en el ámbito de las normas legales, se impone desde una visión legítima del mundo sobre diferentes estilos de vida, la imposición Las normas legales en estos espacios, dentro de una perspectiva racionalista y tecnicista, apoyadas por los principios de generalidad e impersonalidad, a menudo no respetan el conocimiento local de la comunidad y se aplican a través de la verdadera violencia simbólica y el saqueo, incluso si el discurso es una garantía de derechos. Se pretende informar, en base a casos específicos, el papel de los autores en proyectos de mediación de conflictos comunitarios en el estado de Río de Janeiro y en el estado de Bahía. La metodología del trabajo se basa en la teoría fundamentada y el método utilizado fue la investigación bibliográfica realizada a partir de los registros disponibles en fuentes impresas y digitales sobre el Proyecto Balcão de Direitos do ISER, del Programa de Justicia Comunitaria, ambos del estado de Río de Janeiro. , y la Mesa de Justicia y Ciudadanía, en el estado de Bahía. En las discusiones, los autores analizan que los proyectos de mediación de conflictos comunitarios son ejemplos de un intento de crear un puente entre el Estado y la periferia para fomentar / construir un espacio participativo, y que inicialmente tienen como objetivo democratizar el acceso a la justicia para las poblaciones en las regiones periféricas, pero la práctica puede resultar en una violación de los derechos.
\end{abstract}

Palabras clave: proyectos de mediación comunitaria; normas sociales; normas legales; control de prácticas periféricas.

\begin{abstract}
The general objective of the article is to reflect the Brazilian unequal social structure, which, while encompassing a plurality of ways of life, in the sphere of legal norms, imposes itself from a legitimate view of the world on different lifestyles, the imposition of legal norms in these spaces, within a rationalist and technicist perspective, supported by the principles of generality and impersonality, often disrespect the local knowledge of the community and are applied through true symbolic violence and plunder, even if the discourse is a guarantee of rights. It is intended to report, based on specific cases, the role of the authors in community conflict mediation projects in the state of Rio de Janeiro and in the state of Bahia. The methodology of the work is based on the grounded theory and the method used was the bibliographic research carried out from the records available in printed and digital sources about the Project Balcão de Direitos do ISER, of the Community Justice Program, both from the state of Rio de Janeiro , and the Justice and Citizenship Desk, in the state of Bahia. In the discussions, the authors analyze that community conflict mediation projects are examples of an attempt to create a bridge between the State and the periphery to foster / build a participatory space, and that initially aim to democratize access to justice for populations in peripheral regions, but the practice can result in a violation of rights.
\end{abstract}

Keywords: Community mediation projects; social norms; legal norms; control of peripheral practices.

\title{
Introdução
}

O artigo tem por objeto de análise a pluralidade de modos de vida da periferia e a imposição de normais legais nesses espaços, que muitas vezes desrespeitam o saber local da comunidade e são aplicados mediante verdadeira violência simbólica ${ }^{6}$, ainda que o discurso seja de garantia de direitos. No campo legal, estamos diante de normas garantidoras de direitos, conquistadas por luta histórica contra a opressão, por exemplo, o Título II da Constituição Federal de 1988, que elenca os direitos e garantias fundamentais como a

\footnotetext{
${ }^{6}$ Diz respeito a uma forma de violência que se impõe de forma arbitrária e que muitas vezes não é percebida por quem se sujeita a ela (BOURDIEU, 2009).
} 
inviolabilidade do direito à vida, à liberdade, à igualdade, à segurança e à propriedade (art. $5^{\circ}$, caput). A questão que se coloca diante de uma afirmação histórica dos Direitos Humanos (COMPARATO, 2008) é de que forma esses direitos se efetivam na realidade da vida. Será que em um contexto de pluralidades sociais históricas como no Brasil, todos os grupos efetivamente se sentem protegidos apenas pela positivação desses direitos? Bobbio (2004) faz uma reflexão pertinente ao discutir que no campo dos direitos humanos não é a positivação, mas sim a efetivação é que se torna mais problemática.

Serão analisados alguns projetos de mediação comunitária de conflitos, que inicialmente visam democratizar o acesso à justiça às populações de regiões periféricas, com ênfase para os casos concretos no Rio de Janeiro e Bahia. A análise terá como foco a verificação das relações de poder que se operam no espaço social através das normas legais, emanadas pelo Estado, dentro de uma perspectiva racionalista e tecnicista, sustentada pelos princípios de generalidade e impessoalidade, diante de uma realidade plural, marcada pelas desigualdades de acesso e acúmulo de diferentes tipos de capital (BOURDIEU, 2009), entendido de forma ampla, agregando a esfera econômica, social, cultural e simbólica.

O objetivo geral do trabalho é refletir a estrutura social desigual brasileira, que ao mesmo tempo em que abarca uma pluralidade de modos de vida, na esfera das normas legais se impõe a partir de uma visão legítima de mundo sobre estilos de vida distintos, por vezes realizando a pilhagem, deslegitimando e criminalizando práticas sociais, principalmente periféricas. Pretende-se relatar a partir de casos concretos como as normas legais se confrontam no espaço social com normas sociais $^{7}$ (BICHIERI, 2013).

Essas normas podem estar vinculadas a atuação organizativa de movimentos sociais (WOLKMER, 2001), todavia, podem também estar relacionadas ao uso da violência, como no caso das regras estabelecidas pelo tráfico de drogas ou milícias em determinadas regiões do país, o que revela de forma ainda mais evidente os conflitos que envolvem o monopólio da força física, mesmo em um Estado Democrático de Direito. Este universo de diferentes normas evidencia no espaço social o que seriam os fatores reais de $\operatorname{poder}^{8}$ (LASSALE, 2002), ou seja, a construção de relações de poder que não são formalmente estabelecidos, mas que influenciam as práticas sociais.

A metodologia do trabalho baseia-se na teoria fundamentada que tem por base agregar teorias a experiências e dados, com a finalidade de ampliar a compreensão sobre conceitos e

\footnotetext{
${ }^{7}$ Entendidas como normas que influenciam o comportamento e pensamento de dada coletividade (BICHIERI, 2013)

${ }^{8}$ Compreendido como poder de fato que se estabelece mesmo diante de poderes formalmente estabelecidos (LASSALE, 2002).
} 
proporcionar um guia significativo para a ação (STRAUSS, 2002). O método utilizado será uma pesquisa bibliográfica realizada a partir dos registros disponíveis em fontes impressas e digitais sobre a temática, além de registros estatísticos referentes a violações de direitos, e dos dados institucionais referentes ao Projeto Balcão de Direitos, do ISER, em parceria com o Ministério da Justiça e Secretaria Especial dos Direitos Humanos, realizado na favela da Providência, entre 2009 e 2010; o Programa Justiça Comunitária, do Conselho Nacional de Justiça executado pela Secretaria Estadual de Assistência Social e Direitos Humanos do Rio de Janeiro e ISER, na comunidade de Manguinhos, nos anos de 2012 e 2013, ambos na cidade do Rio de Janeiro - RJ; e, dados do Balcão de Justiça e Cidadania da Bahia, em especial os dados publicados pelo órgão e relato de experiência sobre os anos iniciais do projeto na cidade de Salvador/BA.

As atividades empíricas apresentadas na pesquisa são exemplos de uma tentativa de criação de uma ponte entre Estado e periferia para fomentar/construir um espaço participativo, que privilegiasse um saber comprometido com a transformação social, a saber, a capacidade dialógica, inclusiva e reflexiva (GIANNELLA, 2009). O texto pretende abordar experiências que evidenciam a tentativa da busca pelo Direito dentro de uma visão e dimensão transdisciplinar $^{9}$, que busca a ecologia de saberes, e a construção de um conhecimento complexo $^{10}$ (MORIN, 2013; SANTOS, 2007) e situado ${ }^{11}$ (HARAWAY, 1994).

Para abordagem da temática no primeiro item será debatido sobre a estruturação do Estado brasileiro e a aplicação do direito, que pretende ser neutro, mas que ao final é alcançado pelos jogos de poder. No segundo item serão abordados os casos concretos em diálogo com a bibliografia apresentada, e por último as conclusões finais.

\section{O Direito e os jogos de poder}

O Estado brasileiro tem sua construção histórica sobre uma matriz econômica latifundiária e escravocrata, com relações sociais marcadas pela hierarquia e o clientelismo, uma administração pública caracterizada pelo patrimonialismo, e pela reprodução de uma cultura jurídica monista, formal e positivista (WOLKMER, 2001), apesar dos movimentos de contestação da ordem vigente (WOLKMER, BRAVO e FAGUNDES, 2017). A violência inaugural estabelecida na intervenção externa sofrida pelos povos do território foi ponto

\footnotetext{
${ }^{9}$ O princípio aponta para a democracia cognitiva, superando a hierarquização de saberes (SANTOS, 2008).

10 Em uma realidade complexa e multifacetada, as representações mais ricas da realidade são as que se comprometem com a multiplicação dos pontos de vistas (GIANNELLA, 2015).

${ }^{11}$ A noção critica a ideia de um conhecimento universal e total, defende a reflexibilidade e posicionamento do investigador, parcial e localizado.
} 
fundante para o estabelecimento de relações de poder, que definiram os lugares sociais de dominante e dominado. (CLASTRES, 1978).

Ao observar com mais profundidade os conceitos de história, memória e ressentimento no Brasil, o que se verifica são processos de esquecimento e apagamento das pluralidades de visão de mundo, e a reificação física e simbólica do grupo dominante (ARAÚJO, SANTOS, et al., 2020). O pacto social no Brasil, excludente para negros e indígenas, tem sua gênese no não-direito para os escravizados e se construiu a partir de uma caminhada histórica normativa que marcou a garantia dos direitos de forma ampliada, principalmente no que se refere aos aspectos dos direitos civis e políticos, mas que não se perfaz efetiva no que tange a cidadania social (PINHEIRO, 2000).

Segundo Clifford Geertz (1997), o direito não busca a estória real e completa. Os fatos não nascem espontaneamente, eles são construídos socialmente por todos os elementos jurídicos, desde os regulamentos, a etiqueta que regula o comportamento nos tribunais e a retórica dos juízes. Assim, o sentimento de justiça, denominado pelo autor de sensibilidade jurídica varia de acordo com as bases culturais do direito, não só em graus de definição, mas, também no poder que exercem sobre os processos da vida social, frente a outras formas de pensar e sentir.

Foucault $(1979,2013)$ também chama atenção para a construção das formas jurídicas que vão instrumentalizar a busca pela verdade dentro de dada sociedade, sendo importante instrumento de dominação e fonte de análise sobre as relações de poder. Torna-se necessário a reflexão sobre as estruturas que fundamentam os procedimentos de verificação da verdade, uma vez que a criação e utilização dos mesmos exprimem um saber-poder que opera sobre os sujeitos de formas distintas. Portanto, é possível que fatos e leis existam universalmente, mas sua polarização provavelmente não, o direito difere de um lugar ao outro, de uma época a outra, então o que seus olhos vêem também se modifica. O direito pode ter-se tornado secular, mas nem tudo mudou absolutamente, sobretudo as formas da sensibilidade jurídica, ou seja, não perdeu seu relacionamento com a vida local, posto que, o direito é saber local, e, segundo Reale (2000) compreende uma relação dialética, entre fato, valor e norma.

Voltando o olhar para o Brasil, o poder está relacionado a uma maior acumulação histórica de capital que se reflete na força de enunciação de uma visão legítima da realidade sobre outros pontos de vista. A harmonia social que visa à elaboração das normas legais também esconde o poder simbólico que se manifesta de forma arbitrária através dos atributos de impessoalidade e generalidade destas normas sobre uma diversidade social (BOURDIEU, 2009). Será que as normas legais são aplicadas da mesma forma aos casos iguais? São 
aplicadas igualmente, sem distinção de pessoas, sem observar raça, gênero, classe, orientação sexual, religião? De acordo com Wolkmer (2001), nas sociedades industriais avançadas existe uma maior preocupação com as normas distributivas e premiais, enquanto nas sociedades periféricas a ordem normativa se caracteriza pela sua função coercitiva e repressiva, como no caso do Brasil.

Para Bourdieu (2009), o direito é a expressão dos mais fortes, e não é independente, pois há o universo social, local onde se produz e exerce a autoridade jurídica. Este seria um instrumento por excelência da violência simbólica legitima cujo monopólio pertence ao Estado e que pode ser combinada com o exercício da força física. Assim, no campo do direito há concorrência pelo monopólio dos meios jurídicos, pelo direito de dizer o direito. Esta luta se materializa todos os dias na prática, principalmente em locais em que os direitos sociais (art., $6^{\circ}$ da Constituição Federal) não são efetivados de forma plena pelo Estado, locais em que existe um vazio de efetivação de direitos, uma ausência. Mas não existe vazio de poder, então esses territórios são tutelados outras formas e relações de poder, que se interiorizam nas práticas sociais, na forma de pensar e agir, criando assim uma outra noção de normalidade.

Em outras palavras, o direito se estrutura dentro de uma hierarquia de poder, portanto, a Justiça, as instâncias judiciais, as decisões e as interpretações, as normas e fontes conferem a sua autoridade a essas decisões. O direito tem o seu fundamento nele próprio, ou seja, na norma fundamental, na Constituição. Os juristas e os outros teóricos do direito tendem a analisar o direito no sentido da teoria pura, ordenada em sistema autônomo e auto-suficiente. A retórica da autonomia, da neutralidade e da universalidade não é uma simples máscara ideológica, mas sim a expressão de todo o funcionamento do campo jurídico, em especial o trabalho da racionalização ${ }^{12}$. (BOURDIEU, 2009).

A ciência jurídica considera o direito como um sistema fechado e autônomo, cujo desenvolvimento só pode ser compreendido segundo a sua dinâmica interna que valoriza o formalismo (autonomia absoluta da forma jurídica em relação ao mundo social) e o instrumentalismo (o direito é um instrumento para os dominantes). (BOURDIEU, 2009). Assim, diante das afirmações dos autores citados, das contradições na aplicação do direito, as pesquisadoras buscam analisar a pluralidade de modos de vida da periferia e a imposição de normais legais nesses espaços.

\footnotetext{
${ }^{12}$ Os juristas da tradição romano-germânica baseiam-se em regras assentadas em princípios racionais e destinado a ter aplicação universal, ocorre a junção do pensamento teológico (procura a revelação do justo na letra da lei) e do pensamento lógico (pretendem pôr em prática o método dedutivo para aplicar a lei ao caso particular), assim desejam criar uma ciência nomológica que anuncia o dever-se cientificamente. (BOURDIEU, 2009).
} 


\section{Quando o direito sobe e desce morro}

A observação terá como foco a verificação das relações de poder que se operam no espaço social quanto a desigualdade de acesso e acúmulo de diferentes tipos de capital, como econômico, social, cultural e simbólico. O poder está relacionado a uma maior acumulação histórica de capital por determinados grupos, que se reflete na força de enunciação de uma visão legítima da realidade sobre outros pontos de vista. A harmonia social que visa à elaboração das normas legais também esconde o poder simbólico que se manifesta de forma arbitrária através dos atributos de impessoalidade e generalidade destas normas sobre uma diversidade social, podendo ser pensada como uma harmonia coerciva (NADER, 1994).

O que se observa na prática é o conflito pelo monopólio do uso da violência em seu estágio mais crítico, a vida dentro deste espaço busca garantir a sua inviolabilidade de forma contraditória e complexa, a "sociedade" que é cidadã e ao mesmo tempo não é, por que vive todas as formas de exclusão, não acredita no Estado como garantidor de seus direitos, inclusive no que tange ao direito à vida, e busca, na justiça privada (seja pelos meios pacíficos ou não) um caminho para a paz. A inclusão perversa se perfaz na luta ilegítima contra o Estado, a partir do enfrentamento entre normas sociais e normas legais, mas, a mesma se legitima dentro desse seio social enquanto garantidora de valores (não compreensíveis para quem vê de fora) como um viver (ou sobreviver/resistir) em sua dimensão mais plena, independente do seu estágio de marginalização (ARAÚJO e SANTOS, 2019a; ARAÚJO e SANTOS, 2019b).

Assim, a sociedade constrói o marginal, e o elimina através de sua biopolítica negativa, ou seja, instrumentos institucionais de poder que visam garantir a "saúde" da sociedade, eliminando o que a prejudica. E o que se consolida desde o fim da escravatura (1888) é a tentativa de se manter, por outros meios físicos e simbólicos, a figura de determinados sujeitos como inferiores, como não incluídos em uma dimensão mais ampla de direitos humanos, como não integrantes do conceito de dignidade da pessoa humana. E como isso é possível? Através de um processo diário de desumanização, em todos os níveis, desde a não implementação dos direitos sociais até a sua forma mais extrema, o extermínio (ARAÚJO e SANTOS, 2019a; ARAÚJO e SANTOS, 2019b).

Dentro desta realidade de exclusão, algumas tentativas são feitas pelo Estado e/ou sociedade civil no intuito de diminuir a lacuna que existe no que tange o acesso à justiça (mesmo sendo uma garantia constitucional prevista no art. $5^{\circ}, \mathrm{XXXV}$ ). As atividades 
empíricas apresentadas na pesquisa são exemplos de tentativa de criação de uma ponte entre Estado e favela para fomentar/construir um espaço participativo, que privilegiasse um saber comprometido com a transformação social, a saber, a capacidade dialógica inclusiva e reflexiva (GIANNELLA, 2009). O texto pretende narrar experiências que evidenciam a tentativa de ampliação da compreensão do Direito dentro de uma visão disciplinar para uma dimensão transdisciplinar, que busca a ecologia de saberes, e a construção de um conhecimento mais situado (MORIN, 2013; SANTOS, 2007; HARAWAY, 1994).

A mediação comunitária de conflitos apresenta-se como uma prática promovida e facilitada por uma equipe que contribui para a geração de espaços e processos de diálogo participativo, entre indivíduos ou coletivos, com o fim de criar ambientes favoráveis para o manejo e transformação dos conflitos, complementar a justiça e alternativa a violência explicita e implícita. E se estabelece como um processo que torna possível a troca social através do empoderamento, a educação e a construção de redes sociais nas comunidades (OLAVE et al, 2013).

Refletir a partir de experiências possibilita a observação mais aproximada da realidade sobre os desafios da pluralidade social e da necessidade de reflexão sobre formas de insurgências diante da não garantia de direitos (ARENDT, 2013; CAPELLA, 1998, MATTOS, 2008). Quando o direito sobe o morro ele não se vê, porque as normas legais do estado não foram construídas para os cidadãos sem capital, o que se observa (para quem vê de fora) é uma total anormalidade fora de qualquer normativa jurídica, enquanto para os que estão dentro, o que se vê são meios de sobreviver e resistir às múltiplas formas de violências a que estão expostos. Reconstruindo todos os dias sentidos e valores outros, que os permitam o existir, mesmo e em meio a exclusão.

A seguir serão apresentados relatos e dados institucionais referentes ao Projeto Balcão de Direitos e do Programa Justiça Comunitária, ambos na cidade do Rio de Janeiro/RJ, do Balcão de Justiça e Cidadania da Bahia, na cidade de Salvador/BA.

\subsection{Projeto Balcão de Direitos}

Exemplo das problemáticas que discutimos acima pode ser evidenciado pelo relato de experiência do Balcão de Direitos na favela da Providência, no Rio de Janeiro. O Balcão surgiu da mobilização da organização da sociedade civil Viva Rio, e foi apoiado pelo Governo Nacional, se instalou de maneira pioneira em 5 (cinco) favelas do Rio de Janeiro, iniciada no ano de 1996. Uma das principais inovações da iniciativa era traduzir a lei para 
uma linguagem cotidiana através de "oficinas populares de advogados", com objetivo de tratar de direitos dentro das favelas. Dois anos depois de criado, o projeto contou com o apoio da Fundação Ford (1998), e em 2000 foi consolidado como Política Nacional de Direitos Humanos, implementando-se em 17 (dezessete) Estados brasileiros durante os anos seguintes ${ }^{13}$.

Em um primeiro momento o Projeto teve como foco atuar na resolução de direitos mais básicos como documentação, direitos de família, trabalhista e previdenciário, por exemplo. Mas com o tempo o que se percebeu era uma necessidade bem mais ampla por acesso a direitos, que envolvesse a autonomia dos grupos envolvidos e a construção de uma cultura de paz. Assim, o Balcão remodelou sua forma de atuar e também seus objetivos. Em vez de facilitar o acesso ao âmbito judicial, o objetivo se concentrou em fomentar, por meio do diálogo e o entendimento, caminhos não violentos para o tratamento dos conflitos interpessoais, usando para este fim a mediação como prática prioritária (ARAÚJO, 2020).

Na favela da Providência, o Balcão de Direitos foi instalado em 2009. A localidade está situada na região portuária do Rio de Janeiro e é conhecida por ser a primeira a formada na cidade, com população estimada de 4.889 habitantes. De acordo com Araújo (2020), em um primeiro momento, no espaço comunitário coexistiam o tráfico de drogas e o Grupamento de Polícias em Áreas Especiais (GPAE), ambos dividiam pacificamente o monopólio da violência física na região. Para a equipe do Projeto, mesmo com a presença de uma agente comunitária, foi um grande desafio reconhecer as forças que atuavam no território (movimentos sociais e tráfico de drogas), sempre na tentativa de harmonizar as normas legais e as regras locais, rejeitando a violência como forma de resolução de conflitos.

Não foi fácil reconhecer as culturas locais, suas linguagens e práticas e incorporá-los na dinâmica cotidiana dos Centros de Mediação Comunitária, mantendo uma perspectiva transformadora e concreta. Assim, o Centro de Mediação, ao mesmo tempo em que assumia uma opção de manter processos locais, afirmando práticas identitárias de determinado território ou segmento, tinha o desafio igualmente relevante de estimular a contradição e o questionamento destas práticas. Este espírito inquieto exigiu um olhar permeável e atendo dos gestores e mediadores. Assim, de acordo com Araújo (2020, p.120),

Era possível que as pessoas estivessem concretamente vinculadas a diferentes tipos de normas, as legais, que se efetivavam em parte de sua vida civil, por exemplo, quando vinculadas a um trabalho formal, mas também tinham suas moradias reguladas por uma associação de moradores, e poderiam ter o seu direito de

\footnotetext{
${ }^{13}$ OLAVE et al, 2013, p.61.
} 
locomoção limitado pelas normas do tráfico de drogas. Essa dinâmica social criava um corpo próprio de normas que precisava ser identificado e reconhecido pelo Projeto na tentativa de se abrir portas para a criação de um espaço participativo que privilegiasse o diálogo e a cultura local em detrimento das diferentes formas de violência presentes, seja estatal ou comunitária.

Desta forma, em busca de uma constituição de um projeto de "cidadania ativa", com o amadurecimento do Balcão de Direitos se definiram procedimentos que assegurassem a participação equânime entre as normas legais vigentes e as dinâmicas sociais presentes em distintas micro-sociedades que lutam entre si para assegurar a garantia de seus direitos e sua história. Assim, se pode dizer que o Balcão estava projetado para funcionar em áreas de coexistência conflitivas entre regras locais e normas gerais, reconhecendo ambas como válidas.

Participar dessa experiência foi fundamental para meu amadurecimento acadêmico e profissional, pois foi a minha primeira vivência enquanto estudante de Direito em um espaço social conflitivo com as normas legais, e ao mesmo tempo, construtor de suas próprias normas. Essa realidade me permitiu futuramente refletir sobre o digladiar das normas legais e sociais, e seus fundamentos, me atraindo para o campo de estudos biopolíticos ${ }^{14}$.

\subsection{Programa Justiça Comunitária}

O Programa Justiça Comunitária foi idealizado pela juíza do Tribunal de Justiça do Distrito Federal e Territórios (TJDFT), Gláucia Falsarella, há mais de 10 anos. O Programa nasceu em 2000 a partir da experiência do Juizado Especial Cível Itinerante do TJDFT, que buscava atender moradores das comunidades do Distrito Federal que tinham dificuldades de acesso61 à Justiça formal. Nesses dez anos, o Programa se instalou em três regiões administrativas do Distrito Federal: Ceilândia, com 332 mil habitantes, Taguatinga, com 223 mil, e Samambaia, com 147 mil, contando com 60 agentes comunitários capacitados para atuar na mediação de conflitos. Esses agentes compartilhavam a linguagem e o código de valores da região onde moravam, o que auxiliava bastante o entendimento entre as partes e a resolução amigável do conflito (ARAÚJO, 2020).

No Programa Justiça Comunitária, núcleo de Manguinhos (implementado em 2012), na zona norte do Rio de Janeiro, os casos individuais eram distribuídos por especialidades, mas uma vez realizado o primeiro atendimento, os assuntos eram levados para o grupo de técnicos, estagiários e mediadores comunitários, para a discussão coletiva e direcionamentos e

\footnotetext{
${ }^{14}$ Experiência e relato de Danielle Ferreira Medeiro da Silva de Araújo.
} 
encaminhamentos necessários, salvo em casos que demandavam apenas informação. Mas, o corpo técnico não se via como um mediador imparcial, e sim a partir de uma perspectiva de mediação narrativa, que entende o mediador como aquele que não somente assiste as partes na busca de acordos, mas sim como um ator que intervêm na geração de novos significados, novas narrativas e novos espaços sociais de poder (ARAÚJO, 2020). Para Araújo (2018, p.12),

\begin{abstract}
A importância de se criar e/ou fomentar um espaço participativo dentro de um Programa estatal tem o potencial de propiciar resultados positivos para além dos objetivos gerais e específicos delineados por um corpo técnico, além disso, supera a frieza de metas definidas a priori sem que muitas vezes estejam alinhadas com as demandas locais, valoriza a dignidade, fortalece a cidadania social e instrumentaliza os grupos excluídos para luta pelos direitos.
\end{abstract}

Desta forma, os resultados destas iniciativas foram, dentre outros, a abertura de um espaço que compreendesse o sujeito integral, para além do estigma e da exclusão social, um caminho que efetivamente propiciou acesso a novos conhecimentos e novas possibilidades de reconstrução da realidade. O Programa permitiu a riqueza de histórias valiosas de pessoas que buscam o reconhecimento de sua dignidade, ampliando os caminhos para o acesso à justiça, mas também possibilitando oportunidades para o desenvolvimento pessoal, profissional e comunitário.

\title{
2.3. Balcão de Justiça e Cidadania da Bahia
}

O Balcão de Justiça e Cidadania (BJC) foi um programa criado em 2002/2003 ${ }^{15}$ a partir de parceria entre o Tribunal de Justiça da Bahia e Faculdades de Direito, iniciando em Barreiras como projeto piloto e posteriormente aplicado em todo estado da Bahia, com o objetivo de garantir e facilitar o acesso das populações periféricas à Justiça, a partir da mediação e conciliação.

Atuei como estagiária de direito ${ }^{16}$ no início do projeto, no ano de 2004 na comunidade do Curuzu (Salvador/BA), e em 2005 na comunidade da Liberdade (Salvador/BA). O BJC do Curuzu estava localizado na Associação de Moradores, próximo a sede do Ilê Aiyê e o BJC da Liberdade funcionava no Centro Social Urbano da Liberdade. Ao descer do ônibus e andar pelas ruas do Curuzu pela primeira vez fui tomada pela sensação de estranheza, ao perceber que as(os) moradoras(es) saiam de suas casas para ver quem chegava. Quem era a negra de

\footnotetext{
${ }^{15}$ Não há consenso sobre o ano de criação do Balcão de Justiça e Cidadania, alguns documentos citam o ano de 2002, outros 2003.

${ }^{16}$ Relato de Walkyria Chagas da Silva Santos.
} 
cabelo alisado, vestida formalmente e carregando livros? E assim percorri as ruas que levava a sede da Associação e cheguei na cabeça com os sonhos de conseguir resolver as questões jurídicas que seriam ali colocadas pela população, porém, mais do que questões jurídicas fui confrontada por questões sociais que precisam ser resolvidas para que as famílias, as pessoas que buscavam o BJC pudessem conviver a partir de uma cultura de paz.

A equipe do BJC era formada por um advogado supervisor, por agentes locais que auxiliam na chagada das demandas e na organização dos atendimentos e por, no mínimo, duas (dois) estagiários de direito. Antes de iniciar as atividades nós recebíamos capacitação sobre os meios alternativos de resolução de conflitos, com ênfase na mediação e conciliação. No período de atendimento (2004/2005) a maior demanda era por resolução na área de alimentos e briga entre vizinhos. Inicialmente, os envolvidos eram estimulados a conversar e resolver a demanda com a presença de terceiro (estagiária(o) e/ou advogado), caso não encontrassem um solução eram apresentadas alternativas e após o estabelecimento de acordo, este era formalizado a partir de Termo de Acordo que era assinado pelos presentes e encaminhado para homologação para o juiz designado pelo Tribunal de Justiça.

O BJC foi definido como "boa prática" pelo Conselho Nacional de Justiça (CNJ), que deve ser difundida em outros estados para que as populações periféricas tenham acesso a orientação jurídica gratuita e resolução de conflitos na área de família e vizinhança dentro da comunidade em que residem, em especial "conciliações em alimentos, investigação de paternidade, divórcio e separação, além de outras questões como brigas entre vizinhos e dívidas" $" 17$.

A partir da perspectiva de solução de conflitos por meios alternativos, "com os Balcões o conceito da conciliação foi difundido, uma das prioridades da atual Mesa Diretora, e foram evitados novos processos a abarrotar as prateleiras dos cartórios”, e, segundo a desembargadora Silvia Zarif “[...]o mais importante é que promovemos pacificação social e economia para as partes, o Judiciário e a sociedade, que em última análise sustenta o serviço público" ${ }^{18}$.

Em 2010 o CNJ instituiu a Política Nacional de Solução de Conflitos e com ela foram instalados os Centros Judiciários de Solução Consensual de Conflitos (CEJUSC), assim os Balcões de Justiça e Cidadania passaram a ser considerados uma modalidade de CEJUSC,

\footnotetext{
${ }^{17}$ Dados acessados na matéria "Balcão de Justiça e Cidadania bate recordes na Bahia". Disponível em: <https://www.cnj.jus.br/balcao-de-justica-e-cidadania-bate-recordes-na-bahia/>. Acesso em: 25 mai 2020.

${ }^{18}$ Dados acessados na matéria "Balcão de Justiça e Cidadania bate recordes na Bahia". Disponível em: <https://www.cnj.jus.br/balcao-de-justica-e-cidadania-bate-recordes-na-bahia/>. Acesso em: 25 mai 2020.
} 
porém, as unidades da comarca de Salvador conservaram as suas características originais. Segundo dados de 2017/2018,

Desde que começou a funcionar, o Balcão de Justiça e Cidadania promoveu perto de 1 milhão de atendimentos, sem computar as ações desenvolvidas em eventos de cidadania. Foram cerca de 132 mil acordos, beneficiando quase 900 mil pessoas, segundo dados da Assessoria Especial da Presidência. Inicialmente agregados à Assessoria de Ação Social, os balcões já prestavam assistência jurídica, promoviam conciliação e mediação de conflitos de interesse, nas questões cíveis de menor complexidade, como separação judicial, divórcio, fixação de alimentos, regulamentação de visitas e união estável. Ligados atualmente à Assessoria Especial da Presidência II (AEP II), essas unidades, com atuação na autocomposição préprocessual, passaram a integrar a rede do Centro Judiciário de Solução Consensual de Conflitos (Cejusc), conforme determinação do Conselho Nacional de Justiça (CNJ) na Resolução 125.A resolução do CNJ, de novembro de 2010, instituiu a política nacional de solução de conflitos para, nos moldes do que já praticavam os balcões do Tribunal de Justiça da Bahia, buscar a prática da conciliação e mediação por meio da implantação dos Centros Judiciários de Solução Consensual de Conflitos. Embora sejam considerados modalidades do Cejusc, os Balcões de Justiça e Cidadania conservam, na Comarca de Salvador, a característica originária da atuação nos bairros, instalados em locais escolhidos pela própria comunidade beneficiada, a exemplo de prédios de associações de bairro, centros comunitários, escolas e igrejas ${ }^{19}$.

Assim, apesar das dificuldades para a implementação da aplicação do direito a partir de uma visão transdisciplinar, o BJC pode ser apontado como uma tentativa para a construção de uma ponte entre o Estado e a sociedade que resulte em práticas que possibilitem o respeito ao saber local e as especificidades das comunidades atendidas.

\section{Considerações sobre o direito, às relações de poder e as periferias}

As conclusões da pesquisa apontam para a necessidade de uma reflexão crítica das normas legais, da pluralidade social e intelectual de agentes operadores do direito em diferentes posições de poder, da diversificação de formas de democratização de informações sobre direitos, da aproximação da lei geral da realidade social, reconhecendo seus limites e interesses, da instrumentalização dos movimentos populares para lutarem pelos seus direitos, e ampliar os mecanismos de acesso à justiça, concretizando assim, no espaço social de desigualdades históricas, novos caminhos para a realização da cidadania (BITTAR, 2014; BOBBIO, 2004; CAPELLA, 1978).

Há, portanto, a necessidade de se olhar para periferia não como mera receptora de projetos para a imposição do direito monista, mas também como espaço para pensar as

\footnotetext{
${ }^{19}$ Dados acessados na matéria "Unidades do CEJUSC/Balcão de Justiça reforçam a importância da mediação e conciliação". Disponível em: <http://www5.tjba.jus.br/portal/unidades-do-cejusc-balcao-de-justica-reforcam-aimportancia-da-mediacao-e-conciliacao/>. Acesso em: 25 mai 2020.
} 
normas sociais e as pluralidades sociojurídicas presentes no campo social, ou o direito continuará sendo um espaço de demonstração do poder, a partir da sua erudição e imposição, operando verdadeira pilhagem (NADER, 2013) sobre as populações periféricas.

A dualidade da cultura jurídica brasileira se reflete na contemporaneidade com uma Carta Cidadã - Constituição Federal de 1988, composta por direitos e garantias fundamentais, e uma não-efetividade do Estado Democrático de Direito, principalmente para as populações periféricas. Assim, o direito necessita ser olhado a partir de uma visão transdisciplinar para que outros modos de vida que não o hegemônico seja considerado para sua elaboração e aplicação.

Se é certo que o direito é mais um instrumento de poder nas mãos dos dominadores, expressão de força dos mais fortes, ele também, nas palavras de Roberto Lyra Filho, “[...] é processo, dentro do processo histórico: não é uma coisa feita, perfeita e acabada; é aquele vira-ser que se enriquece nos movimentos de libertação das classes e grupos ascendentes". (LYRA FILHO, 1982). E é esse vir-a-ser que as populações periféricas buscam no direito quando a ele recorre para resolver seus conflitos.

Repensar as práticas periféricas fora do lugar de anormalidade, marginalização e estigmatização torna-se fundamental para se discutir as bases desiguais que fundamentam as relações de poder no país, e também como as mesmas se impõem invisivelmente com violência simbólica sob uma pluralidade de modos de vida. A abertura de espaço como o acadêmico para outros olhares a partir desses lugares pode se configurar como importante estratégia de luta e resistência contra o apagamento e a exclusão.

\section{Referências}

ARAÚJO, Danielle Ferreira Medeiro da Silva de. Espaços participativos e o uso de metodologias integrativas para a efetividade de direitos. Revista NAU Social, v.09, n.16, p. 67 $-80,2018$.

Mediação Comunitária: um relato de experiência sobre a tensão entre normas legais e normas sociais em favelas do Rio de Janeiro. In: MARCHIORI NETO, Daniel Lena; RABBANI, Roberto Muhájir Rahnemay; MEDEIROS, Orione Dantas de. (Orgs.). Estudos contemporâneos sobre Direito, Estado e Sociedade. Série Direito, Estado e Sociedade, v. 2, Rio Grande: Ed. da Furg, 2020.

ARAÚJO, Danielle Ferreira Medeiro da Silva de; CHAGAS, Walkyria Santos. Raça como elemento central da política de morte no Brasil: visitando os ensinamentos de Roberto Esposito e Achille Mbembe. Rev. Direito Práx., Rio de Janeiro, v.10, n.4, p. 3024-3055, 2019a. 
Constituição de 1988 e juventude negra: para a desconstrução de um dispositivo tanatológico. In: FILPO, Klever; MIRANDA, Maria Geralda; SILVA, Rogerio Borba da; PEREIRA, Thiago Rodrigues (Org.). Direitos humanos e fundamentais em perspectiva. Rio de Janeiro: Ágora21, 2019b.

ARAÚJO, Danielle Ferreira M.S; SANTOS, Walkyria Chagas S; FERNANDES, Alexandre O; CAMPOS, Leonardo L. História, memória e ressentimento: revisitando a trajetória de exclusão da população negra no Brasil. Revista Latinoamericana de Estudios en Cultura y Sociedad-RELACULT, v. 06, ed. especial, mar., 2020.

ARENDT, HANNAH. Crises da República. São Paulo: Perspectiva. 2013.

BICHIERI. Cristina. Norms, conventions and the power of expectations. To appear in Philosophy of Social Science, N.Cartwright and E. Montuschi, eds., Oxford University Press, 2013.

BITTAR, Eduardo C. B. O direito na Pós-modernidade. 3.ed. São Paulo: Atlas, 2014.

BOBBIO, Norberto. A era dos direitos. Trad. de Carlos Nelson Coutinho. Rio de Janeiro: Elsevier, 2004.

BOURDIEU, Pierre. O poder simbólico. Tradução: Fernando Tomaz. 12 ed. Rio de Janeiro: Bertrand Brasil, 2009.

CAPELLA, Juan Ramón. Os cidadãos servos. Porto Alegre: Fabris, 1998.

COMPARATO, Fábio Konder. A afirmação histórica dos Direitos Humanos. Editora Saraiva. 2008.

CLASTRES, Pierre. A Sociedade Contra o Estado. Rio de Janeiro: Francisco Alves Editora S.A. 1978.

FOUCAULT, Michel. Microfísica do Poder. Trad. Roberto Machado. Rio de Janeiro: Edições Graal, 1979.

A verdade e as formas jurídicas. Rio de Janeiro: Editora NAU, 2013.

GEERTZ, Clifford. "O saber local: fatos e leis em uma perspectiva comparada". In.: GEERTZ, Clifford. $O$ saber local: fatos e leis em uma perspectiva comparada. $2^{\text {a }}$ ed. Petrópolis: Vozes, (1999[1997]).

GIANNELLA, Valéria. Espaço aberto para trocas: uma oficina sobre os paradoxos da mobilização social em contextos de exclusão extrema. Coleção Roteiros Gestão Social, v.1. Salvador: CIAGS/UFBA, 2009.

HARAWAY, Donna. Um manifesto para os ciborgs: ciência, tecnologia e feminismo socialista na década de 80. In: HOLLANDA, Heloísa Buarque de (Orgs.). Tendências $e$ impasses: o feminismo como crítica da cultura. Rio de Janeiro: Rocco, 1994. 
LASSALE, Ferdinand. $O$ que é uma Constituição? Trad. Walter Stonner. Edições e Publicações Brasil: São Paulo, 2002.

LYRA FILHO, Roberto. O que é o direito. 11. Ed. São Paulo: Editora Brasiliense, 1982.

MATTOS, Wilson Roberto de. Negros contra a ordem: astúcias, resistências e liberdades possíveis (Salvador, 1850-1888). Salvador: EDUNEB, EDUFBA, 2008.

MORIN, Edgar. A religação de saberes. Rio de Janeiro: Bertrand Brasil. 2013.

NADER, Laura. "A pilhagem e o estado de Direito". In: MATTEI, Ugo e NADER, Laura. Pilhagem. Quando o estado de direito é ilegal. São Paulo: Martins Fontes, 2013.

Harmonia coerciva: a economia política dos modelos jurídicos. Revista Brasileira de Ciências Sociais, São Paulo, v. 9, n. 26, p. 18-29, 1994.

OLAVE, Rosa María et al. Guía de Mediación Comunitaria. Programa de las Naciones Unidas para los Asentamientos Humanos (ONU-HABITAT) en copublicación con Universidad Alberto Hurtado de Chile e Instituto de Estudios de la Religión ISER, 2013.

PINHEIRO, Paulo Sérgio. Democracia, violência e injustiça: o Não - Estado de Direito na América Latina. Org. Juan E. Méndez, Guilhermo O’Donnell, Paulo Sérgio Pinheiro, trad. Ana Luiza Pinheiro, Octacilio Nunes, São Paulo: paz e terra, 2000.

REALE, Miguel. Experiência e cultura. Campinas: Bookseller. 2000.

SANTOS, Boaventura de Sousa. Para além do pensamento abissal: das linhas globais a uma ecologia dos saberes. Revista Novos Estudos, n. 79, novembro, 2007.

STRAUSS, Anselm; CORBIN, Juliet. Bases de la investigación cualitativa: técnicas e procedimentos para desarrollarlateoría fundamentada. Trad: Eva Zimmerman. Colombia: Editorial Universidad de Antioquia, deciembre, 2002.

WOLKMER, Antônio Carlos. Pluralismo Jurídico: Fundamentos de uma nova cultura no Direito. São Paulo: Editora Alfa Ômega. 2001.

WOLKMER, Antônio Carlos; BRAVO, Efendy Emiliano Maldonado; FAGUNDES, Lucas Machado. Historicidade Crítica do Constitucionalismo Latino- Americano e Caribenho. Rev. Direito e Práx., Rio de Janeiro, v. 08, n.4, p. 2843-2881, 2017. 